\title{
Analysis of checklists for agricultural safety management
}

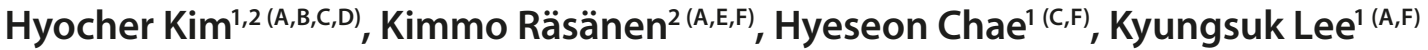 \\ ${ }^{1}$ National Institute of Agricultural Science, Rural Development Administration, Korea \\ ${ }^{2}$ Institute of Public Health and Clinical Nutrition, Faculty of Health Sciences, University of Eastern Finland, Kuopio \\ Campus, Finland \\ A - Research concept and design, B - Collection and/or assembly of data, C - Data analysis and interpretation, \\ $D$ - Writing the article, E - Critical revision of the article, F - Final approval of article
}

Kim H, Räsänen K, Chae H, Lee K. Analysis of checklists for agricultural safety management. Ann Agric Environ Med. $2018 ; 25(3)$ : 494-499. doi: $10.26444 / a a e m / 85177$

\begin{abstract}
Introduction. The current health and safety management system under the Occupational Health and Safety Act has avoided agriculture in Korea. It is important to consider the various safety systems used in agricultural health and safety to develop effective regulations.

Objective. The aims were to classify and review the items from various checklists using safety systems, such as design, training, etc., ultimately aimed at proposing directions for improving the health and safety of farmers.

Materials and method. Among the retrieved checklists with Google, four were chosen for this study, based on criteria such as the Checklist developed by an international organization, as well as others. Each item on the checklist was categorized using criteria concerning safety systems, developed based on previous studies.

Results. The total number of analyzed items was 573, which is 36 more than the actual number of checklist items (537). The proportion of items belonging to the training/procedures system was the highest (32.5\%); the second-highest was for the mitigation system $-18.2 \%$; the third-largest proportion of items was maintenance/inspection - with $14.3 \%$. Items related to the design and human factor systems were $8.2 \%$ and $5.6 \%$, respectively. The safety system with the lowest proportion was the warning/notification system $-4.2 \%$ of the total items. The proportion of items that could not be classified into safety systems was found to be $16.1 \%$.

Conclusions. A large number of items belonging to the training/procedures system reported as occasionally not effective in prevention of injury were found in the checklists. It appears important to develop checklist items proposing the supplementation of various safety systems, rather than presenting items that are biased towards certain safety systems.
\end{abstract}

Key words

checklist, agriculture, safety, management

\section{INTRODUCTION}

Agriculture is known to be one of the most dangerous industries in the world along with mining and forestry. However, health and safety management in agriculture is challenging compared to other industries due to difficulties in accessibility caused by geographical dispersion, smaller size of farming businesses, diversity of farms and farm work, management by self-employed farmers, aging of farmers, a wide range of potential hazards from use of agricultural machinery to animals [1-6]. Due to these factors, there is a lack of health and safety regulations specifically for agriculture, even in Western countries; also in Korea, the current health and safety management system under the Occupational Health and Safety Act has largely avoided agriculture [79]. Only recently, countries such as the United States have begun to apply health and safety regulations to agriculture, previously not applicable to self-employed farmers, and separate regulations have been introduced for specific sources of hazards, such as agricultural machinery $[10,11]$. Given the general lack of agricultural health and safety regulations, health and safety institutions in Finland and Ireland, as well as

Address for correspondence: Hyeseon Chae, National Institute of Agricultural Science, Rural Development Administration of Korea, 310 nosaengmyeng-ro, 54875 Jeonju, Korea (South)

e-mail: hyeseon@korea.kr

Received: 27.09.2017; accepted: 09.02.2018; first published: 13.04.2018 the International Labour Organization (ILO), have developed health and safety checklists for agriculture, utilizing them in intervention programmes where farmers or local experts directly evaluate and manage risks associated with farms.

It has been reported that agricultural health and safety intervention programmes focused on training and education have had uncertain effects on the improvement of health and safety levels in farms [12]. In order to develop effective prevention methods for occupational injuries among farmers, it is important to consider errors in the various safety systems, ranging from the lack of training and failure to use personal protective equipment, to the deficient design of agricultural machinery, misuse of safety signs, and presence of language barriers [13-16].

While items in agricultural health and safety checklists such as utilization of personal protective equipment, safety education, and adherence to safe procedures, can be easily applied to self-employed farmers with limited financial resources, checklists using a diverse range of safety systems can be an important tool for supplementing health and safety regulations and used as guidelines for more effective health and safety interventions. Therefore, this study aimed to classify and review the items from various checklists using safety systems, such as safety design, training, safety signs, communication, etc., ultimately aiming to propose directions for improving health and safety checklists used in farm workplaces, as well as improving safety regulations. 


\section{MATERIALS AND METHOD}

Checklist search. To collect agricultural health and safety checklists utilized in farms, on 6 January 2016, Google was used to search for checklists, accumulating a total of 54 checklists. The following key words and phrases were used in the search: agriculture, checklist, accident, disease, health, safety, farmers, farm workers, risks, hazards, and management. No limit for publication year was introduced. Among the retrieved checklists, four were chosen for this study based on the following criteria:

a) checklist developed by an international organization, national health and safety authority, or agricultural association in Western countries;

b) checklist suitable for use on any type of farm, including self-employed and family farms;

c) checklist written to be easily understood by farmers (Tab. 1).

Categorizing items into safety systems. In this study, each of the checklist items was categorized using criteria concerning safety systems, developed based on previous studies (Tab. 2). The definition of each system in this study varies slightly from that suggested in previous research, given that agricultural workplace conditions are different from those in other industries $[2,17]$. The items that could not be classified into the domains of the six safety systems were labeled as 'not categorized' (NC) items.

\section{RESULTS}

Classification of checklist items according to safety systems and sub-systems. Table 3 shows the results of the classification of all checklist items based on the safety systems presented in Table 2. Where one item belonged to more than two safety systems or NC group, the item was divided and classified. As a result, the total number of analyzed items was 573, which is 36 more than the actual number of checklist items (537).

In all four checklists, the proportion of items belonging to the training/procedures system was the highest. The checklist with the highest proportion of these items was the 'Checklist for maintenance activities in agriculture' - 37.3\%, and the checklist with the lowest proportion was the 'Risk assessment tool' $-28.9 \%$. Summing-up all items, the proportion of items belonging to the training/procedures system was $32.5 \%$. The second-highest proportion was for the mitigation system, with $18.2 \%$ of items belonging to this system, and ranged between $16.1 \%-21.0 \%$ across the checklists. The safety system with the third-largest proportion of items was maintenance/ inspection, with $14.3 \%$. However, in the checklist 'Ergonomic checkpoints in agriculture', the proportion of items in this system was only $3.8 \%$, representing a much lower proportion compared to other checklists. Items related to the design and human factor systems were $8.2 \%$ and $5.6 \%$, respectively, and had similar proportions. The safety system with the lowest proportion was the warning/notification system $-4.2 \%$ of the total items. The proportion of items in this system was low with less than $6 \%$ in all checklists (Tab. 3, 4).

Classification of checklist items not categorized into safety systems and sub-systems. The proportion of items that could not be classified into safety systems was found to be $16.1 \%$. In terms of individual checklists, the 'Checklist for maintenance activities in agriculture' had the lowest proportion of NC items - 5.6\%, and the ILO-developed checklist 'Ergonomic checkpoints in Agriculture' had the highest - 28.5\%. Among the NC items, the proportion of items with indefinite target or method was 5.9\%; again, 'Ergonomic checkpoints in Agriculture' had the highest proportion at $11.4 \%$, and the 'Checklist for maintenance activities in agriculture' the lowest $-1.9 \%$. The overall proportion of NC items, excluding those with indefinite target or method, was $11.2 \%$ (Tab. 3). Within the NC category, the items enquiring about farmers' recognition of the existence of hazards were mostly found in the 'Risk assessment document'. In the 'Risk assessment tool', there were 9 and 10 items relating to general health management and administrative action, respectively, which were significantly higher numbers than in the other checklists. In the 'Ergonomic checkpoints in agriculture' there were 5 and 9 items relating to environmental protection and management of workplace and work, including work shift, respectively (Tab. 4).

Table 1. Characteristics of checklists for analysis

\begin{tabular}{|c|c|c|c|c|}
\hline Checklist name & Category classification & $\begin{array}{l}\text { Number } \\
\text { of items }\end{array}$ & Publisher/Country & Source \\
\hline $\begin{array}{l}\text { Ergonomic } \\
\text { checkpoints in } \\
\text { agriculture }\end{array}$ & $\begin{array}{l}\text { Storage and handling of materials, Workstations and tools, Machine } \\
\text { safety, Agricultural vehicles, Physical environment, Control of hazardous } \\
\text { chemicals, Environmental protection, Welfare facilities, Family and } \\
\text { community cooperation, Work organization and working schedules }\end{array}$ & 100 & $\begin{array}{l}\text { International } \\
\text { Labour } \\
\text { Organization (ILO) }\end{array}$ & $\begin{array}{l}\text { http:/www.ilo.org/global/publications/ } \\
\text { ilo-bookstore/order-online/books/ } \\
\text { WCMS_168042/lang--en/index.htm }\end{array}$ \\
\hline $\begin{array}{l}\text { Checklist for } \\
\text { maintenance } \\
\text { activities in }_{\text {agriculture }^{\mathrm{a}}}\end{array}$ & $\begin{array}{l}\text { Information and training, Falls on the farm, Roof work, Scaffolds and } \\
\text { platforms, Building demolition, Portable tools, Workshop, Machinery } \\
\text { repair, Vehicle repair, Power take-off safety, Fire safety in workplaces, } \\
\text { Electricity, Fuses and miniature circuit-breakers, Confined spaces, Farm } \\
\text { infections, Sun and heat exposure }\end{array}$ & 152 & $\begin{array}{l}\text { European Agency } \\
\text { for Safety and } \\
\text { Health at Work } \\
\text { (EU-OSHA) }\end{array}$ & $\begin{array}{l}\text { https://osha.europa.eu/en/tools-and- } \\
\text { publications/publications/reports/ } \\
\text { maintenance-in-agriculture-a-safety-and- } \\
\text { health-guide }\end{array}$ \\
\hline $\begin{array}{l}\text { Risk assessment } \\
\text { document }^{\text {b }}\end{array}$ & $\begin{array}{l}\text { Children, Older farm household members, Tractors, Farm vehicles and } \\
\text { ATVs, Machinery, Livestock, Farmyard and buildings, Workshop/repairs/ } \\
\text { working with timber, Electricity, Chemical safety assessment, Health of } \\
\text { farmers }\end{array}$ & 113 & $\begin{array}{l}\text { Health and Safety } \\
\text { Authority } \\
\text { (Ireland) }\end{array}$ & $\begin{array}{l}\text { http://www.hsa.ie/eng/Publications_- } \\
\text { and_Forms/Publications/Agriculture_- } \\
\text { and_Forestry/Code_of_Practice_-_Risk_ } \\
\text { Assessments.pdf }\end{array}$ \\
\hline $\begin{array}{l}\text { Risk assessment } \\
\text { toolc }\end{array}$ & $\begin{array}{l}\text { Noise, Thermal conditions, Footpaths and workspaces, Chemicals, } \\
\text { Dust and molds, Machinery and equipment, Hand tools, Electricity and } \\
\text { electronic equipment, Physical workloads, Operational planning, Animal } \\
\text { handling, Transport and traffic, Timber cutting and fire wood making }\end{array}$ & 172 & $\begin{array}{l}\text { National } \\
\text { Resources } \\
\text { Institute (Finland) }\end{array}$ & $\begin{array}{l}\text { https://portal.mtt.fi/portal/page/portal/ } \\
\text { mtt/hankkeet/maatilanriskienhallinta/ } \\
\text { tyoturvallisuusriskit b.pdf }\end{array}$ \\
\hline
\end{tabular}

a This checklist is contained in "Maintenance in Agriculture - A Safety and Health Guide" (European Agency for Safety and Health at Work, 2011)

"This checklist is contained in "Farm Safety Code of Practice" (Health and Safety Authority, Ireland, 2006)

'Original Finnish title of the checklist is Työturvallisuusriskien hallinta, b-osa (Occupational safety risk management, part b) and the checklist was found through website of Natural Resources Institute, Finland and translated by Prof. Kimmo Räsänen of University of Eastern Finland, one of the authors. 
Table 2. Definition of safety systems and sub-systems

\begin{tabular}{|c|c|}
\hline Safety systems & Sub-systems \\
\hline $\begin{array}{l}\text { Design } \\
\text { (Safety system eliminating or substituting hazard } \\
\text { on farm) }\end{array}$ & $\begin{array}{l}\text { - Elimination or substitution of hazard } \\
\text { - Safety design of agricultural machinery, workplace, infrastructure, tool, storage material } \\
\text { - Existence of proper tools, machinery, infrastructure, facilities for safety } \\
\text { - Designation of safe place for vulnerable people } \\
\text { - Storage of hazardous materials away from workplace }\end{array}$ \\
\hline $\begin{array}{l}\text { Maintenance/inspection } \\
\text { (Safety system inspecting or maintaining safety } \\
\text { status) }\end{array}$ & $\begin{array}{l}\text { - Maintenance and inspection of infrastructure, machinery, facilities, safety devices, and workplace } \\
\text { - Hazard assessment } \\
\text { - Inspection of work ability }\end{array}$ \\
\hline $\begin{array}{l}\text { Mitigation } \\
\text { (Safety system reducing or minimizing exposure to } \\
\text { hazard and injury) }\end{array}$ & $\begin{array}{l}\text { - Shutdown devices or blocking of sources of hazards } \\
\text { - Supporting or securing devices } \\
\text { - Reduction of weight and electricity } \\
\text { - Existence of ventilation system } \\
\text { - Existence of seatbelt, guard, and safety rail } \\
\text { - First aid preparedness } \\
\text { - Existence of emergency facility or devices } \\
\text { - Rollover protection } \\
\text { - Existence of rest or safe areas away from hazards } \\
\text { - Ergonomic design of workplace and materials, and devices } \\
\text { - Enough spaces, sockets and others for safety }\end{array}$ \\
\hline $\begin{array}{l}\text { Warning/notification } \\
\text { (Safety system raising alarm or notifying work about } \\
\text { hazard) }\end{array}$ & $\begin{array}{l}\text { - Existence of sign or board for notification and warning } \\
\text { - Existence of easy-to-see visual display of control } \\
\text { - Existence of communication system for emergency situations such as alarming device } \\
\text { - Material Safety Data Sheets available in workplaces }\end{array}$ \\
\hline $\begin{array}{l}\text { Training/procedures } \\
\text { (Safety system making farmer act safely during } \\
\text { work) }\end{array}$ & $\begin{array}{l}\text { - Existence and observance of procedures for safe task } \\
\text { (stable posture, pre-startup review, wearing seatbelt, turning off engine, clear visibility, positioning of } \\
\text { materials, use of proper tools, working slowly, and buddy system) } \\
\text { - Retention of information related to safety } \\
\text { - Training and education for safety and health } \\
\text { - Work performed by certified personnel }\end{array}$ \\
\hline
\end{tabular}

Human factor

(Safety system protecting each farmer individually - Use of personal protective equipment (PPE), sunscreens, work clothes and others for personal safety from hazard on farm)

- Indefinite target (injury and hazard) or method

- Administrative action

- Environmental protection

NC

- Outsourcing of hazardous work

(Not categorized by safety systems) _ - Public sanitation

- General health management

- Farmers' recognition of hazard in workplace

- Management of work and environment

Table 3. Number of checklist items $(\mathrm{N}=573)$ categorized by safety systems (\%)

\begin{tabular}{|c|c|c|c|c|c|}
\hline \multirow[b]{2}{*}{ Safety system } & \multicolumn{4}{|c|}{ Checklist name } & \multirow[b]{2}{*}{ Total } \\
\hline & $\begin{array}{l}\text { Ergonomic } \\
\text { checkpoints in } \\
\text { agriculture (ILO) }\end{array}$ & $\begin{array}{l}\text { Checklist for maintenance } \\
\text { activities in agriculture } \\
\text { (EU-OSHA) }\end{array}$ & $\begin{array}{c}\text { Risk assessment } \\
\text { document (Ireland) }\end{array}$ & $\begin{array}{l}\text { Risk assessment tool } \\
\text { (Finland) }\end{array}$ & \\
\hline Number of items & 100 & 152 & 113 & 172 & 537 \\
\hline [Number of items divisible into two or more] & {$[5]$} & [9] & {$[7]^{b}$} & {$[15]$} & [36] \\
\hline Design & $10(9.5)$ & $21(13.0)$ & $3(2.5)$ & $13(7.0)$ & $47(8.2)$ \\
\hline Maintenance /inspection & $4(3.8)$ & $26(16.1)$ & $22(18.3)$ & $30(16.0)$ & $82(14.3)$ \\
\hline Mitigation & $22(21.0)$ & $26(16.1)$ & $25(20.8)$ & $31(16.6)$ & $104(18.2)$ \\
\hline Warning /communication & $5(4.8)$ & $9(5.6)$ & $6(5.0)$ & $4(2.1)$ & $24(4.2)$ \\
\hline Training /procedures & $32(30.5)$ & $60(37.3)$ & $40(33.3)$ & $54(28.9)$ & $186(32.5)$ \\
\hline Human factor & $2(1.9)$ & $10(6.2)$ & $6(5.0)$ & $14(7.5)$ & $32(5.6)$ \\
\hline Indefinite target (injury/hazard) or method & $12(11.4)$ & $3(1.9)$ & $10(8.3)$ & $9(4.8)$ & $34(5.9)$ \\
\hline Total number of items & $105(100)$ & $161(100)$ & $120(100)$ & $187(100)$ & $573(100)$ \\
\hline
\end{tabular}

administrative action, outsourcing of hazardous work, environmental protection, public sanitation, general health management, farmers' recognition of hazard in workplace, management of work and environment, hazard identification

${ }^{\mathrm{b}}$ An item is divisible into three 
Table 4. Number of checklist items $(\mathrm{N}=573)$ categorized by sub systems in each safety system (\%)

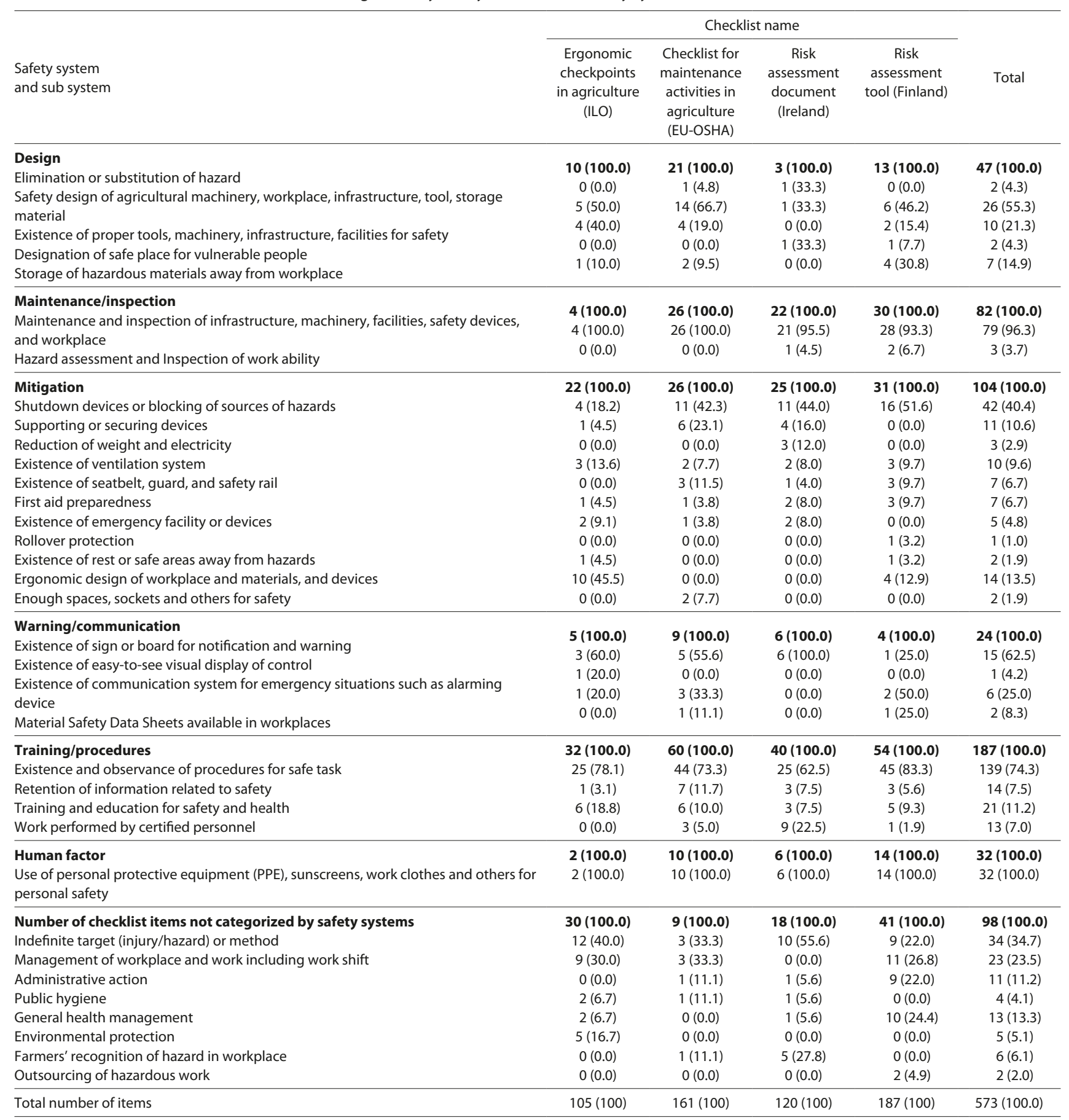

\section{DISCUSSION}

It is well known that occupational injuries during farm work typically occur due to the rotating blades of agricultural machinery or exposure from dangerous chemicals, such as pesticide. However, to ensure the effective and direct prevention of occupational injuries during farm work, it is important to verify not only the level of exposure to source of hazards and risk factors, but also the factors that influence the occurrence of occupational injuries from a management perspective.

According to previous studies, the occupational injuries faced by farmers are associated with farm management conditions and their socio-economic status [18, 19]. Kim et al. (2016) stated that farmers' occupational injuries occur due to errors in various safety systems, such as inefficient design of machines, lack of communication tools such as warning signs, and lack of training.

The current study analyzed and classified the items in four existing agricultural health and safety checklists into six safety systems suggested by Kim et al. (2016), presenting considerations for improving future agricultural health and safety checklists, as well as regulations [2].

Analyzing the checklists, the highest proportion of items was found for the training/procedures system, followed by the mitigation and maintenance/inspection systems. The fact 
that checking for participation in training and observance of procedures for safe tasks is comparatively the easiest assessment, may have resulted in the highest number of items for the training/procedures system. Moreover, the assumption that inadequate awareness, knowledge, and attitudes may result in behaviors causing injuries might have contributed to the inclusion of a high number of items related to training and work procedures for farmers during checklist development. However, it has been confirmed that health and safety intervention programmes in agriculture implemented through education and training are occasionally ineffective [20].

Deroo et al. (2000) insisted that many specialists argued that safety management involving the adjustment of workplace environments or system changes through legislation amendments is more effective in reducing injuries, compared to educational programmes [21]. The authors of the presented study believe that the reason behind such phenomena can be attributed to the possibility that engaging in actions for health and safety according to training depends on the individual's level of understanding and acceptance of the training, as well as the workplace environment. Moreover, farmers' occupational injuries are deeply and complexly connected to various errors, such as faulty design of agricultural machinery as well as human error [22-25]. Thus, in order to advance injury prevention efficiency, it is more important to consider other safety systems than focusing only on the training/procedural system.

The proportion of items categorized into the mitigation and maintenance/inspection systems was found to be the highest after the training/procedures system. The presented study defined the mitigation system as ranging from ventilation devices and removal of hazardous airborne substances to emergency shut-down devices for agricultural machinery. While these systems do not present a fundamental solution, e.g. eliminating or substituting hazards, they may still be very effective, as prevention effects can be sustainable regardless of the attitude of farmers. However, in the same way that continuous education is required to maintain workers' knowledge of health and safety, maintenance and inspection are also mandatory. In the checklists examined in this study, there were many items for confirming the status of maintenance and repairs of safety equipment. Given that the proportion of items in the mitigation and maintenance/ inspection systems was the second highest, the checklists analyzed in this study may be effective to a certain extent in hazard prevention for farmers.

The most effective prevention method for occupational injuries is the elimination or substitution of hazards that result in injuries. This study defined such methods as the design system and identified items from each checklist belonging to this category. However, in farm workplaces, crops, livestock, and agro-products are sources of hazards that are difficult to eliminate; moreover, despite design errors in agricultural machinery being sources of safety hazards, the replacement of such machinery or facilities may be difficult for self-employed farms given their financial situation, which become even more pronounced in developing countries. As a result, it is certainly understandable that the items belonging to the design system had a comparatively lower proportion. However, from the perspective of securing the right to know for farmers, it appears necessary to develop and utilize checklist items for a design system that is more proactive in nature.
In the presented study, the proportion of items within the warning/notification system was the lowest. Agriculture is characterized by individual work, with farmers separated geographically from one another; this characteristic appears to have been reflected in the analyzed checklists, resulting in a lower number of items belonging to the warning/notification system, which is consistent with the communication existing between farmers. Workers may not be able to notice warning/ notification signs or hear an alarm due to their unique situation. Moreover, the level of understanding of signage may differ according to the educational level of farmers; consequently, this renders equality in health and safety management for all workers very difficult, similar to the shortfall in the training/procedures system. Language barriers also present problems in health and safety management in agriculture [3], and many studies are being carried out in areas of occupational safety on the functions and positive effects of safety sign and warning label design [26, 27]. Given the characteristics of farm work, with rising numbers of aged farmers and foreign workers, it appears critical to recognize the value of warning/notification items.

According to the safety systems used in this study, some items were identified as being unclassifiable. As such, items relating to public sanitation, general health management, and environmental protection were not classified under systems of safety, as they refer to the general level of safety management rather than to the prevention and management of specific occupational injuries. Moreover, items related to the administrative action of recording and preserving safety documents were not classified into safety systems, as administrative management cannot be clearly defined in its direct causal association with occupational injuries.

Despite the existence of agricultural health and safety checklists developed by private institutions and academia, this study limited its analysis to checklists developed by national institutions or international organizations. Therefore, further research is required to review a more diverse range of items on health and safety management, and include checklists developed by private organizations, such as agricultural and insurance companies, universities, and research institutions.

Kim et al. (2016) engaged in the analysis of causes of farmers' occupational injuries using the logic tree analysis, which confirmed that most safety incidents occur as a result of the accumulation of various errors in safety systems, rather than due to simple exposure to hazards or mistakes by workers [2]. However, the authors of the current study argue that the most optimal checklist for preventing farmers' occupational injuries should include the maximum number of items classifiable within the safety systems presented in this study. For example, in case of asphyxia in a confined workplace, items such as 'measurement of oxygen concentration in a confined space' (maintenance/inspection system), 'operation of ventilation system' (mitigation system), 'installation of warning signs' (warning/notification system), 'collaborative work involving two or more workers and training in working within a confined space' (training/ procedures system), and 'equipping oxygenators' (human factor system) can be presented simultaneously. Similarly, multi-layered solutions must be presented for the case of a single injury in order to increase farmers' understanding of the case and its prevention, leading to more effective prevention of occupational injury. 


\section{CONCLUSIONS}

Occupational injuries in agriculture occur when individuals are exposed to risk factors, where such exposure coincides with errors in a diverse range of safety systems. This indicates that when devising management strategies to prevent a certain type of occupational injuries, it can be more effective in safety management to present improvements in a diverse range of system errors, rather than fixing errors in a specific system. This study found a large number of checklist items belonging to the training/procedures and mitigation system. For the development of effective and substantial agricultural health and safety checklists or regulations in the future, it appears important to consider overlapped actual errors in safety systems according to each injury type, and develop corresponding checklist items proposing the supplementation of such systems, rather than presenting items that are biased towards certain safety systems or providing simple safety management information.

\section{Acknowledgement}

This work was carried out with the support of "Cooperative Research Program for Agriculture Science and Technology Development (Project No. PJ01007903)" Rural Development Administration, Republic of Korea.

\section{REFERENCES}

1. Karttunen JP, Rautiainen RH. Distribution and characteristics of occupational injuries and diseases among farmers: A retrospective analysis of workers' compensation claims. Am J Ind Med. 2013; 56(8): 856-69.

2. Kim H, Lee K, Räsänen K. Agricultural injuries in Korea and errors in systems of safety. Ann Agric Environ Med. 2016; 23(3): 432-6.

3. McCurdy SA, Carroll DJ. Agricultural injury. Am J Ind Med. 2000; 38(4): 463-80

4. Sprince NL, Park H, Zwerling C, Lynch CF, Whitten PS, Thu K, et al. Risk Factors for Animal-related Injury Among lowa Large-livestock Farmers: A Case-control Study Nested in the Agricultural Health Study. J Rural Health. 2003; 19(2): 165-73.

5. Nilsson K, Nilsson K, Pinzke S, Pinzke S, Lundqvist P, Lundqvist P. Occupational injuries to senior farmers in Sweden. J Agric Saf Health. 2010; 16(1): 19-29.

6. Virtanen SV, Notkola V, Luukkonen R, Eskola E, Kurppa K. Work injuries among Finnish farmers: A National Register Linkage study 1996-1997. Am J Ind Med. 2003; 43(3): 314-25.

7. Reed S, Douphrate DI, Lundqvist P, Jarvie P, McLean G, Koehncke N, et al. Occupational Health and Safety Regulations in the Dairy Industry. J Agromedicine. 2013; 18(3): 210-8.
8. Liebman AK, Wiggins MF, Fraser C, Levin J, Sidebottom J, Arcury TA. Occupational health policy and immigrant workers in the agriculture, forestry, and fishing sector. Am J Ind Med. 2013; 56(8): 975-84.

9. Calvert GM, Lee K, Roh S, Davis KG, Tak S. Promoting and protecting worker health and safety in the Republic of Korea agricultural sector. J Agromed. 2012; 17(3): 326-37.

10. Somervell PD, Conway GA. Does the small farm exemption cost lives? Am J Ind Med. 2011; 54(6): 461-6.

11. Beer SR, Field WE. Analysis of factors contributing to 674 agricultural driveline-related injuries and fatalities documented between 1970 to 2003. J Agromed. 2005; 10(3): 3-19.

12. Lehtola MM, Rautiainen RH, Day LM, Schonstein E, Suutarinen J, Salminen S, et al. Effectiveness of interventions in preventing injuries in agriculture-a systematic review and meta-analysis. Scand J Work Environ Health. 2008; 34(5): 327-36.

13. Dźwiarek M. An analysis of accidents caused by improper functioning of machine control systems. Int J Occup Saf Ergon. 2003; 10(2): 129-36.

14. Kaustell KO, Mattila TEA, Rautiainen RH. Barriers and enabling factors for safety improvements on farms in Finland. J Agric Saf Health. 2011; 17(4): 327-42.

15. Scott P, Kogi K, McPhee B. Ergonomics guidelines for occupational health practice in industrially developing countries. IEA and $\mathrm{ICOH} ; 2010$. p. 15.

16. Makin AM, Winder C. A new conceptual framework to improve the application of occupational health and safety management systems. Saf Sci. 2008; 46: 935-48.

17. Anderson J, Collins M, Devlin J, Renner P. Using Hazard Maps to Identify and Eliminate Workplace Hazards: A Union-Led Health and Safety Training Program. New Solut. 2012; 22(3): 325-42.

18. Kim S-K, Kim H, Lee K, Kang H-T, Oh S-S, Ko SB. The Relationship between Injury and Socioeconomic Status in Reference to the Fourth Korean National Health and Nutrition Examination Survey. Ann Occup Environ Med. 2014; 26(1): 1.

19. Suutarinen J. Management as a risk factor for farm injuries. J Agric Saf Health. 2003; 10(1): 39-50.

20. Rautiainen RH, Lehtola MM, Day LM, Schonstein E, Suutarinen $\mathrm{J}$, Salminen S, et al. Interventions for preventing injuries in the agricultural industry. Cochrane Database Syst Rev. 2008; 1: CD006398.

21. DeRoo LA, Rautiainen RH. A systematic review of farm safety interventions. Am J Prev Med. 2000; 18(4): 51-62.

22. Dekker SWA. Accidents are normal and human error does not exist: a new look at the creation of occupational safety. Int J Occup Saf Ergon. 2003; 9(2): 211-8.

23. Mattila TEA, Kaustell KO, Rautiainen RH, Pitkanen TJ, Lotjonen T, Suutarinen J. Slip, trip and fall injuries in potato, sugar beet and open field vegetable production in Finland. Ergonomics. 2008; 51(12): 1944-59.

24. Marcum JL, mccann, Browning SR, Reed DB, Charnigo RJ. Farmworkrelated injury among farmers 50 years of age and older in Kentucky and South Carolina: a cohort study, 2002-2005. J Agric Saf Health. 2011; 17(3): 259-73.

25. Dosman J, Hagel L, King N, Koehncke N, Kirychuk S, Trask C, et al. The Hierarchy of Control in the Epidemic of Farm Injury. J Agromed. 2015; 20(3): 360-9.

26. Laughery KR. Safety communications: Warnings. Appl Ergon. 2006; 37(4): 467-78.

27. Lesch MF. Warning symbols as reminders of hazards: Impact of training. Acc Anal Prev. 2008; 40(3): 1005-12. 